\title{
Perceptions of healthcare professionals towards palliative care in internal medicine wards: a cross-sectional survey
}

\author{
Jason Tay ${ }^{1}$, Scott Compton², Gillian Phua ${ }^{3}$, Qingyuan Zhuang ${ }^{3}$, Shirlyn Neo ${ }^{3}$, Guozhang Lee ${ }^{1}$, Limin Wijaya ${ }^{2,4}$, \\ Min Chiam ${ }^{5^{*}}$ (D) Natalie Woong ${ }^{1}$ and Lalit Krishna ${ }^{2,3,5,6,7,8}$
}

\begin{abstract}
Background: The extension of palliative care services to meet the needs of patients with chronic non-malignant life-limiting conditions faces misconceptions amongst healthcare professionals. A study of prevailing perceptions of healthcare professionals on this wider palliative care service was thus conducted to identify current obstacles, guide the education of local healthcare professionals and improve service accessibility.

Methods: A cross-sectional study was carried out at the Singapore General Hospital. An anonymised and closeended online questionnaire was disseminated to 120 physicians and 500 nurses in the Department of Internal Medicine. The online survey tool focused on participant demographics; perceptions of palliative care and its perceived benefits; roles and indications; and attitudes and behaviours towards palliative care referrals.

Results: Forty four physicians and 156 nurses suggested that care of terminally ill patients with chronic nonmalignant life-limiting conditions are compromised by concerns over the role of palliative care in non-cancer care and lapses in their prognostication and communication skills. Respondents also raised concerns about their ability to confront sociocultural issues and introduce palliative care services to patients and their families.

Conclusions: Gaps in understanding and the ability of nurses and physicians to communicate end of life issues, introduce palliative care services to patients and their families and confront sociocultural issues suggest the need for a longitudinal training program. With similar concerns likely prevalent in other clinical settings within this island nation, a concerted national education program targeting obstacles surrounding effective palliative care should be considered.
\end{abstract}

Keywords: Education and training, End of life, Internal medicine, Nurses, Palliative care, Palliative medicine, Physicians, Quality of life

\footnotetext{
* Correspondence: chiam.min@nccs.com.sg

${ }^{5}$ Division of Cancer Education, National Cancer Centre Singapore, 11 Hospital Crescent, Singapore 169610, Singapore

Full list of author information is available at the end of the article
}

(c) The Author(s). 2021 Open Access This article is licensed under a Creative Commons Attribution 4.0 International License, which permits use, sharing, adaptation, distribution and reproduction in any medium or format, as long as you give appropriate credit to the original author(s) and the source, provide a link to the Creative Commons licence, and indicate if changes were made. The images or other third party material in this article are included in the article's Creative Commons licence, unless indicated otherwise in a credit line to the material. If material is not included in the article's Creative Commons licence and your intended use is not permitted by statutory regulation or exceeds the permitted use, you will need to obtain permission directly from the copyright holder. To view a copy of this licence, visit http://creativecommons.org/licenses/by/4.0/. The Creative Commons Public Domain Dedication waiver (http://creativecommons.org/publicdomain/zero/1.0/) applies to the data made available in this article, unless otherwise stated in a credit line to the data. 


\section{Background}

Whilst palliative care services have been credited with improving the quality of life of terminally ill cancer patients and providing holistic support for families, its role in the care of patients with non-cancer diagnoses and chronic life-limiting conditions remains poorly understood by healthcare professionals [1-5]. A study by the Lien Foundation in Singapore found that $74 \%$ of the 200 physicians and $46 \%$ of the 400 nurses surveyed reported inadequate understanding of palliative care's role [5]. These gaps in understanding and misconceptions on the role of palliative care interventions have been identified as significant barriers to referrals and the utilisation of palliative care services $[3,4]$.

With data suggesting that unmet needs, symptom severity and psychosocial distress of patients with endstage non-malignant diseases are comparable to patients with cancer, poor utilisation of palliative care and delayed referrals are likely to result in prolonged symptom burden. The need to improve awareness of palliative care's role amongst healthcare professionals in internal medicine wards is evident [6-10]. This has come into sharp focus in Singapore as the Department of Internal Medicine at the Singapore General Hospital, a local tertiary hospital with an inpatient palliative care consultation service focused on non-cancer care, seeks to extend its palliative care services to chronic nonmalignant life-limiting conditions.

Serving as primary users of this extended service, the team at the Department of Internal Medicine sought to survey and better understand perceptions, and misconceptions, of palliative care amongst physicians and nurses in the department, with careful attention towards conceptual differences raised between the two populations. Data accrued will be used to further guide and inform their palliative care education.

\section{Methods}

To design the survey, the research team reviewed recent studies on perceptions of palliative care amongst healthcare professionals [11-26]. These reviews allowed the research team to draw up a set of survey questions focused on answering the primary research question "how do physicians and nurses perceive palliative care and its role in the management of patients with terminal illnesses?" The potential questions for the survey were discussed amongst the research team and adapted to account for practice and work schedules.

A cross-sectional study involving physicians $(n=120)$ and nurses $(n=500)$ from the Department of Internal Medicine was carried out at Singapore General Hospital. Study exemption was accorded by the SingHealth Centralised Institutional Review Board (CIRB reference no. 2019/2396).
All physicians - including consultants, registrars, medical and house medical officers, and nurses - including enrolled, registered nurses, nurse clinicians and managers were invited to participate in this anonymised and close-ended online questionnaire.

The survey was categorised into three distinct domains:

(1) Participant demographics relating to clinical and palliative care experience.

(2) Perceptions of palliative care with a focus on perceived benefits, ${ }^{1}$ roles and indications of consultation referrals. ${ }^{2}$

(3) Self-reported behaviours so as to identify potential obstacles in initiating palliative care - these include participants' confidence in explaining the role of palliative care to patients, ${ }^{3}$ confusion with palliative terminologies ${ }^{4}$ and views on palliative care training and utilisation. ${ }^{5}$

Email invitations replete with a participant information sheet and a link to the self-administered survey were disseminated by the department secretary and nursing managers. Two reminder emails were sent out over the course of the next 2 weeks.

Categorical variables (such as demographic data) and ordinal variables (such as Likert scale ratings) between physicians and nurses were analysed using chi-square or Wilcoxon Rank Sums tests. To aid in the interpretation of the ordinal responses, means and standard deviations are presented. All $p$-values are associated with nonparametric tests. All analyses were conducted using SPSS Software (SPSS, Inc., Chicago, IL, USA, version 26).

\section{Results}

Demographics, clinical and palliative care experience

Of the 200 healthcare professionals who participated in the study, 44 (22\%) were physicians and 156 (88\%) were nurses (Table 1). The response rate was $32.3 \%$.

Nearly $50 \%$ of the physicians who responded had less than 5 years of clinical experience whilst approximately $80 \%$ of the nurses who responded had more than 5 years

\footnotetext{
${ }^{1}$ A five-point Likert scale was used ( $1=$ not at all beneficial, $2=$ not so beneficial, 3 = somewhat beneficial, 4 = beneficial, 5 = very beneficial). ${ }^{2}$ A five-point Likert scale was used ( $1=$ not at all important, $2=$ not so important, 3 = somewhat important, $4=$ important, 5 = very important).

${ }^{3}$ A five-point Likert scale was used ( $1=$ not at all confident, $2=$ not so confident, 3 = somewhat confident, $4=$ confident, 5 = very confident).

${ }^{4}$ A five-point Likert scale was used ( $1=$ not at all confusing, $2=$ not so confusing, 3 = somewhat confusing, $4=$ confusing, 5 = very confusing).

${ }^{5}$ A five-point Likert scale was used 1 = strongly disagree, 2 = disagree, 3 = neutral, 4 = agree, 5 = strongly agree).
} 
Table 1 Participant characteristics

\begin{tabular}{|c|c|c|c|}
\hline & $\begin{array}{l}\text { Physicians } \\
(n=44)\end{array}$ & $\begin{array}{l}\text { Nurses } \\
(n=156)\end{array}$ & $p$-value \\
\hline \multicolumn{4}{|l|}{ Years' Experience* $\mathrm{n}(\%)$ selecting } \\
\hline$<5$ Years & $22(48.9)$ & $32(20.5)$ & \\
\hline$>5$ to 10 Years & $15(33.3)$ & $65(41.7)$ & 0.001 \\
\hline$>10$ to 20 Years & $5(11.4)$ & $50(32.1)$ & \\
\hline$>20$ years & $2(4.4)$ & $9(5.8)$ & \\
\hline At least "frequently" interacts with terminally ill patients* $n(\%)$ agree & $35(79.5)$ & $111(71.2)$ & 0.268 \\
\hline \multicolumn{4}{|l|}{ Where did you first learn of palliative care?* $n(\%)$ selecting } \\
\hline Medical or Nursing School & $33(76.7)$ & $88(58.3)$ & \\
\hline Workplace & $7(16.3)$ & $62(41.1)$ & 0.002 \\
\hline Family or friends & $2(4.7)$ & $1(0.7)$ & \\
\hline Media & $1(2.3)$ & $0(0.0)$ & \\
\hline \multicolumn{4}{|l|}{ Are you aware of any palliative care services in your hospital/institution?* $n(\%)$ yes } \\
\hline When you hear of the term hospice, what do you first think of?* $n(\%)$ selecting & $43(97.7)$ & $143(94.7)$ & 0.400 \\
\hline A place for cancer patients & $0(0.0)$ & $14(9.0)$ & \\
\hline A place where all hope is lost & $2(4.5)$ & $6(3.8)$ & 0.109 \\
\hline A place for pain medication titration and control & $4(9.1)$ & $5(3.2)$ & \\
\hline A place for palliation and optimising quality of life & $38(86.4)$ & $128(82.1)$ & \\
\hline A place for elderly patients & $0(0.0)$ & $3(1.9)$ & \\
\hline
\end{tabular}

† Based on the following options: "very frequent"; "frequent"; "occasionally"; "rarely"; "never"

All p-values for * obtained from chi square test

of clinical experience. Both groups reported having frequent interactions with terminally ill patients despite different work schedules and practice settings, particularly with junior physicians often rotating through different specialities and clinical settings.

Physicians and nurses were introduced to palliative care in medical and nursing school respectively. Whilst nearly $98 \%$ of physicians and $95 \%$ of nurses were aware of palliative care services in their hospital, close to $15 \%$ of nurses were uncertain as to what palliative care entailed (Table 2). Most physicians and nurses were also aware of hospices although some had different conceptualisations of their role. Approximately $86 \%$ of physicians and $82 \%$ of nurses saw hospice care as "a place for palliation and optimising quality of life". Close to $10 \%$ of nurses saw hospices as being "a place for cancer patients".

\section{Indications for palliative care referral}

Physicians and nurses acknowledged the import of palliative care amongst patients with terminal illnesses, with mean scores of 4.84 and 4.72 respectively on a 5-point Likert scale (Table 2). Both groups placed similar importance upon palliative care for physical symptom control, psychological and emotional support, and discharge and placement planning.
However, nurses tended to believe that elderly patients and patients with dementia were less likely to benefit from palliative care (3.74 vs $4.30, p=0.001)$.

While majority of the physicians and nurses viewed difficulty prognosticating their patients' disease progression as the biggest barrier to palliative care referrals (59.1 and $43.7 \%$ respectively), nearly $20 \%$ of nurses also believed that referral to palliative care could be construed by the patient as abandonment. About $11 \%$ of nurses also believed palliative care referrals could be financially costly.

\section{Self-reported behaviours}

Only about $43 \%$ of nurses would discuss issues regarding the extent of care and care determinations with their patients and only $42 \%$ of nurses would always "have conversations about palliative care to terminally ill patients". This contrasts starkly with physicians who reported that they would "speak about the extent of care" and care determinations with their patients and "have conversations about palliative care to terminally ill patients" (88.9\% and $77.8 \%$ respectively, vs $42.9 \%$ and $41.7 \%, p=0.001$ ).

However, nurses were more likely than physicians to discuss palliative care options when patients are first diagnosed with a life limiting illness $(73.7 \%$ vs $34.9 \%, p=$ 
Table 2 Perceptions of palliative care

\begin{tabular}{|c|c|c|c|}
\hline & $\begin{array}{l}\text { Physicians } \\
(n=44)\end{array}$ & $\begin{array}{l}\text { Nurses } \\
(n=156)\end{array}$ & $p$-value \\
\hline $\begin{array}{l}\text { How important do you think the role of palliative medicine is in the care of } \\
\text { terminally ill patients?* Mean }(+/-s d)\end{array}$ & $4.84(0.43)$ & $4.72(0.48)$ & 0.076 \\
\hline \multicolumn{4}{|l|}{$\begin{array}{l}\text { How beneficial do you think each patient group will benefit from palliative } \\
\text { care?+ Mean }(+/- \text { sd) }\end{array}$} \\
\hline Elderly Patients & $4.11(0.84)$ & $4.16(0.74)$ & 0.910 \\
\hline Patients with Dementia & $4.30(0.79)$ & $3.74(0.98)$ & 0.001 \\
\hline Patients with Cancer & $4.95(0.21)$ & $4.65(0.59)$ & 0.001 \\
\hline Patients with Organ Failure & $4.80(0.46)$ & $4.48(0.66)$ & 0.002 \\
\hline \multicolumn{4}{|c|}{ How important do you think each of the following indications are for palliative care referral?* Mean (+/-sd) } \\
\hline Physical symptom control & $4.7(0.55)$ & $4.6(0.60)$ & 0.160 \\
\hline Psychological/emotional support & $4.4(0.70)$ & $4.5(0.65)$ & 0.612 \\
\hline Discharge/placement planning & $4.0(0.96)$ & $4.4(0.71)$ & 0.016 \\
\hline
\end{tabular}

Which of the following do you feel is the biggest barrier in considering/recommending a referral to palliative care for your patient? $\neq \mathrm{n}(\%)$ selecting

Own uncertainty about what palliative care entails

Difficulty in prognostication / Unpredictable course disease

$3(6.8) \quad 22(14.6)$

Patients' fear of abandonment

$26(59.1) \quad 66(43.7)$

Patients' fear of abar

$5(11.4) \quad 30(19.9)$

0.037

I have no difficulties or concerns

$1(2.3) \quad 17(11.3)$

$9(20.5) \quad 16(10.6)$

* As measured on the following scale: 1 "not at all important"; 2 "not so important"; 3 "somewhat important"; 4 "important"; 5 "very important"

† As measured on the following scale: 1 "not at all beneficial"; 2 "not so beneficial"; 3 "somewhat beneficial"; 4 "beneficial"; 5 "very beneficial"

All p-values for * and + obtained from Wilcoxon Rank Sums test

All $p$-values for $\neq$ obtained from chi square test

0.001). Nearly $11 \%$ of physicians would defer to the palliative care team to discuss these issues whilst $89 \%$ of physicians would include the family in these discussions.

Other disparities in introducing palliative care and approaches to end of life conversations between the participants are summarised in Table 3.

There was strong agreement that more stakeholders involved should be educated or trained in palliative care. High mean scores ranging from 4 to 4.6 were observed for statements such as "Nurses should be included more in end of life conversations", "There should be more palliative training to healthcare workers" and "The general public does not know enough about palliative care".

\section{Subgroup analysis}

Subgroup analysis of our survey was performed comparing senior (consultants and registrars) versus junior (house and medical officers) physicians, and senior (nursing clinicians and managers) versus junior (enrolled and registered) nurses (Table 4). Senior physicians reported being more confident in explaining the role of palliative care to their patients as compared to junior physicians (3.95 vs $3.42, p=0.020$ ), but no statistical difference was noted between senior and junior nurses. There was also no statistical difference between senior and junior physicians, and senior and junior nurses, with regards to initiating a referral upon first diagnosis of a life-limiting illness or at symptom onset.

\section{Discussion}

In answering its primary research question, this study revealed that a large majority of nurses and physicians at the Department of Internal Medicine at Singapore General Hospital recognise the importance of palliative care. However, effective utilisation of palliative care services continues to be undermined by gaps in knowledge, prognostication and communication. These gaps appear to stem from unfamiliarity with palliative care's shift from a prognosis-based model to a needs-based model and failure to appreciate its merits in supporting patients with non-cancer diagnoses and chronic life-limiting conditions [27]. Indeed, this study reveals that misconceptions on the role of prognosis as an entry criteria inhibit up to $60 \%$ of physician initiated referrals to palliative care.

Scrutiny of the data captured in this survey also highlights different misconceptions between physicians and nurses about palliative care. Physicians tend to see palliative care services as being primarily for the palliation of physical symptoms in terminally ill cancer and noncancer patients and do not seem to appreciate palliative care's role in providing emotional and psychological support. Physicians also appear to be less likely to 
Table 3 Self-reported behaviours

\begin{tabular}{|c|c|c|c|}
\hline & $\begin{array}{l}\text { Physicians } \\
(n=44)\end{array}$ & $\begin{array}{l}\text { Nurses } \\
(n=156)\end{array}$ & $p$-value \\
\hline Always speak about extent of care to terminally ill patients* $n(\%)$ agree & $40(88.9)$ & $67(42.9)$ & 0.001 \\
\hline Always have conversations about palliative care to terminally ill patients* $n(\%)$ agree & $35(77.8)$ & $65(41.7)$ & 0.001 \\
\hline \multicolumn{4}{|l|}{ When would you consider a referral to palliative care?* $n(\%)$ agree } \\
\hline When first diagnosed with life limiting illness & $15(34.9)$ & $115(73.7)$ & 0.001 \\
\hline At symptom onset & $43(97.7)$ & $128(82.6)$ & 0.011 \\
\hline When illness becomes terminal & $44(100.0)$ & $150(96.2)$ & 0.187 \\
\hline If family or patient demonstrate distress & $40(93.0)$ & $113(72.4)$ & 0.005 \\
\hline How confident are you in explaining the role of palliative care to patients? + Mean $(+/-s d)$ & $3.7(0.74)$ & $3.2(0.86)$ & 0.001 \\
\hline \multicolumn{4}{|l|}{ How do you first communicate the option of palliative care to patients and families?* $n(\%)$ selecting } \\
\hline Hold a patient and/or family conference & 39 (88.6) & $57(37.7)$ & \\
\hline Refer to palliative care & $5(11.4)$ & $87(57.6)$ & 0.001 \\
\hline Do not broach topic & $0(0.0)$ & $7(4.6)$ & \\
\hline \multicolumn{4}{|c|}{ How confusing do you find the different terminologies used (e.g terminal care, best supportive care, comfort care) are? $\neq$ Mean $(+/ s d)$} \\
\hline $\begin{array}{l}\text { How much do you agree or disagree with the following statements about palliative } \\
\text { care? } \S \text { Mean }(+/- \text { sd) }\end{array}$ & $2.7(1.06)$ & $2.7(0.98)$ & 0.855 \\
\hline PC referrals are an underutilized service & $3.6(0.99)$ & $3.4(1.06)$ & 0.184 \\
\hline Nurses should be included more in end of life conversations & $4.3(0.59)$ & $4.0(0.80)$ & 0.015 \\
\hline There should be more PC training to healthcare workers & $4.6(0.50)$ & $4.2(0.72)$ & 0.003 \\
\hline The general public does not know enough about PC & $4.6(0.54)$ & $4.2(0.82)$ & 0.007 \\
\hline
\end{tabular}

† As measured on the following scale: 1 "not at all confident"; 2 "not so confident"; 3 "somewhat confident"; 4 "confident"; 5 "very confident"

₹ As measured on the following scale: 1 "not at all confusing"; 2 "not so confusing"; 3 "somewhat confusing"; 4 "confusing"; 5 "very confusing"

§ As measured on the following scale: 1 "strongly disagree"; 2 "disagree"; 3 "neutral"; 4 "agree"; 5 "strongly agree"

All p-values for * obtained from chi square test

All p-values for $\dagger$, $\neq$ and $\S$ obtained from Wilcoxon Rank Sums test

appreciate palliative care's role in providing longitudinal support for patients and their families upon discharge as highlighted by lesser tendencies to refer appropriate cases to palliative care services.

Nurses in this study, on the other hand, appreciated palliative care's holistic and longitudinal support even after hospital discharge. However, they were also more likely to voice concerns over their prognostication and communication skills and more likely to struggle when contending with sociocultural nuances. This may be reflected in the fact that up to $58 \%$ of nurses were unlikely to introduce or discuss palliative care services with patients and up to $60 \%$ who preferred to defer to the palliative care team to introduce themselves and their roles.

Table 4 Seniors vs Juniors

\begin{tabular}{lll}
$\begin{array}{l}\text { Senior Physicians } \\
(\boldsymbol{n}=\mathbf{2 2})\end{array}$ & $\begin{array}{l}\text { Junior Physicians } \\
(\boldsymbol{n}=\mathbf{2 1})\end{array}$ & $\boldsymbol{p}$-value \\
$6(28.6)$ & $8(38.1)$ & 0.513 \\
$21(95.5)$ & $21(100)$ & 0.323 \\
$3.95(0.6)$ & $3.42(0.8)$ & 0.020 \\
$\begin{array}{l}\text { Senior Nurses } \\
(\boldsymbol{n}=\mathbf{4 5 )}\end{array}$ & $\begin{array}{l}\text { Junior Nurses } \\
(\boldsymbol{n}=\mathbf{1 1 1})\end{array}$ & $\boldsymbol{p}$-value \\
& & \\
$32(71.1)$ & $83(74.8)$ & 0.638 \\
$34(75.6)$ & $94(85.5)$ & 0.140 \\
$3.07(0.8)$ & $3.24(0.9)$ & 0.273 \\
\hline
\end{tabular}

When would you consider a referral to palliative care?* $n(\%)$ agree

When first diagnosed with life limiting illness

At symptom onset

How confident are you in explaining the role of palliative care to patients?+ Mean $(+/-s d)$

† As measured on the following scale: 1 "not at all confident"; 2 "not so confident"; 3 "somewhat confident"; 4 "confident"; 5 "very confident"

When would you consider a referral to palliative care?* $n(\%)$ agree

When first diagnosed with life limiting illness

$32(71.1)$

At symptom onset

All p-values for * obtained from chi square test

All $p$-values for $t$, $\neq$ and $\S$ obtained from Wilcoxon Rank Sums test 
Underlining these lapses in understanding of palliative care and reaffirming the need for effective education of physicians and nurses on a national scale is the impact of regnant sociocultural considerations on local end of life practices. Ho et al. [28]'s, Krishna [29]'s, Yang et al. [30]'s, Foo et al. [31]'s, Chai et al. [32]'s and Ching et al. [33]'s studies which posit that prevailing sociocultural beliefs, particularly those attributed to Confucian based concepts of filial piety [34-41], may hamper the expansion of palliative and hospice care [29, 42-45] are particularly noteworthy here. These notions may shed further light on culturally-entrenched motivations behind delays to early and appropriate referrals.

There are three local interpretations of filial piety that have been especially influential to local end of life care $[28,46,47]$. One is the duty to 'maintain hope'. Failure of the family and caregivers to do so is believed to precipitate depression and the hastening of death $[48,49]$. This wish to 'maintain hope' has been seen to propagate local practice of collusion [43, 50, 51], resulting in families rejecting palliative and hospice care services to 'protect' the patient from 'bad' news. Such rejection is also attributed to another closely related local interpretation of filial piety - the duty of 'non-abandonment' [29]. As hospice care may suggest that a 'cure' is no longer possible, acceptance of a referral may be viewed as tantamount to abandonment of the patient and the loss of hope. Recommending such care may be a cause of concern for local healthcare professionals as highlighted by nearly $20 \%$ of the nurses and more than $10 \%$ of the physicians in this survey. This leads to the third local interpretation of filial piety which is the duty of 'continued support'. This relates to family-led care and support of the patient. A family's failure to meet this duty is fed in part by the mistaken belief that involvement of hospice and palliative care interventions would lead to reduced family involvement. This misconception is rooted in the notion that the 'immediate' role of the family would be diminished, at least with regards to the provision of the patient's physical care. Acceptance of palliative and hospice care is thus regarded as unacceptable behaviour. These three interrelated [52] local interpretations of filial piety colours notions of palliative care $[29,42-45,53]$ as does the oft-assumed concept of 'hospice related care' which paints hospices as merely 'somewhere to go to die' [54].

The combination of knowledge gaps, unfamiliarity with prognostication and the changing roles of palliative and hospice care may explain why few physicians in this survey would consider initiating a referral upon first diagnosis of a life-limiting illness. Rodriguez et al. [55]. suggest that such hesitancy may in part stem from the dated notion that palliative care consultations are 'reserved' for patients at the end of life. Our data further suggests that such misconceptions pervade all levels of training and experience, affirming the need for more stakeholder engagement in the form of a two-pronged approach - advancing knowledge and skills in palliative care and addressing sociocultural misconceptions.

In line with the World Health Organisation's recommendation that requisite levels of competence in palliative care be rendered compulsory in basic medical professional qualifications [56], establishing common awareness and adherence to national strategies and guidelines such as those delineated by the Singapore Hospice Council should be considered in the curation and early stages of local palliative care education programs [57]. Returning to the concept of a needs-driven palliative care, training in palliative care amongst healthcare workers are imperative. These programs must include strategies to equip healthcare professionals with skills in prognostic communications $[58,59]$ and the use of validated needs assessment tools. Use of evidence based methods and care approaches will enhance confidence of healthcare professionals and help evolve local understanding. Standardised instruments such as the Integrated Palliative Care Outcome Scale (IPOS) and Palliative Care Needs Assessment Tool: Progressive Disease-Heart Failure (NAT: PD-HF) may help physicians and nurses identify patients who could benefit from palliative care involvement $[60,61]$.

As a result of survey findings and prevailing data of a wider 'existential' threat to wider, non-cancer related referrals for palliative care services evidenced in recent studies in Singapore, further training programs focusing on changing minds, enhancing cultural sensitivity and equipping healthcare professionals with requisite clinical and communication skills ought to be planned. In tandem, further engagement with the public is proposed to overcome socioculturally related misconceptions and to enhance understanding of palliative and hospice care's role to all patients that need them.

\section{Study limitations}

Although our study had a considerable $32.3 \%$ response rate, the low response rate of $22 \%$ among physicians may not be representative and constitutes a limitation of this study. As our survey was distributed to participants within the hospital's internal medicine department, it may not be generalisable to other medical subspecialities or surgical specialties where the threshold for specialist palliative care referral may differ. Limited to physicians and nurses, our results do not represent all members of the multidisciplinary team which may also include social workers, therapists and pharmacists. As levels of palliative care training received by physicians and nurses were not ascertained, palliative-trained internists or nurses 
could have influenced perceptions and the study's results.

\section{Conclusions}

We believe this survey of physician and nurse perceptions of palliative care in internal medicine in Singapore General Hospital reflects a wider gap in understanding of palliative care in Singapore, given the presence of corroborative findings on gaps in communication and prognostication skills and a general misunderstanding of palliative care's role amongst physicians and nurses. Given such wide ranging knowledge and skill gaps and misconceptions, we opine that there is a need for a concerted national education program to target these barriers to palliative care's effective use as they likely persist across clinical settings. This program must focus on increasing communication skills and cultural sensitivity even as government led initiatives on educating the public to palliative care's wider role continue. At the same time this data also lends weight to efforts by local medical and nursing schools to increase awareness of palliative care. We hope that these insights will be of use to our colleagues in Southeast Asia and beyond and we look forward to continuing this discussion.

\section{Abbreviations \\ SGH: Singapore General Hospital; IPOS: Integrated Palliative Care Outcome Scale; NAT: PD-HF: Palliative Care Needs Assessment Tool: Progressive Disease-Heart Failure; COPD: Chronic obstructive pulmonary disease}

\section{Acknowledgements}

Assistance provided by Ms. Alexia Sze Inn Lee for reviewing and formatting the paper was greatly appreciated.

\section{Authors' contributions}

JT and LK were involved in research design and planning, investigation, analysis, reflection, manuscript writing and review. SC, GP, QYZ, SN, GZL, LW, $M C$ and NW were involved in analysis, reflection, manuscript writing and review. Each author has approved the submitted version (and any substantially modified version that involves the author's contribution to the study) and have agreed both to be personally accountable for the author's own contributions and to ensure that questions related to the accuracy or integrity of any part of the work, even ones in which the author was not personally involved, are appropriately investigated, resolved, and the resolution documented in the literature.

\section{Funding}

No funding was received for this study.

\section{Availability of data and materials}

The datasets used and/or analysed during the current study are available from the corresponding author on reasonable request.

\section{Declarations}

\section{Ethics approval and consent to participate}

IRB exemption was accorded by the SingHealth Centralised Institutional Review Board (CIRB reference no. 2019/2396). Consent was implied upon the respondents' participation in the voluntary, anonymous and selfadministered survey. No identifiers were collected. The questionnaire form further indicated that survey responses would be used for research purposes only.

\section{Consent for publication}

NA

\section{Competing interests}

The authors declare that they have no competing interests.

\section{Author details}

${ }^{1}$ Department of Internal Medicine, Singapore General Hospital, Outram Rd, Singapore 169608, Singapore. ${ }^{2}$ Duke-NUS Medical School, 8 College Road, Singapore 169857, Singapore. ${ }^{3}$ Division of Supportive and Palliative Care, National Cancer Centre Singapore, 11 Hospital Crescent, Singapore 169610, Singapore. ${ }^{4}$ Department of Infectious Diseases, Singapore General Hospital, Outram Road, Singapore 169608, Singapore. ${ }^{5}$ Division of Cancer Education, National Cancer Centre Singapore, 11 Hospital Crescent, Singapore 169610, Singapore. ${ }^{6}$ Palliative Care Institute Liverpool, Academic Palliative \& End of Life Care Centre, University of Liverpool, United Kingdom Cancer Research Centre, University of Liverpool, 200 London Rd, Liverpool L3 9TA, UK. ${ }^{7}$ Centre for Biomedical Ethics, National University of Singapore, Blk MD 11, 10 Medical Drive \#02-03, Singapore 117597, Singapore. ${ }^{8}$ PalC, The Palliative Care Centre for Excellence in Research and Education, 10 Jalan Tan Tock Seng, Singapore 30843, Singapore.

Received: 13 November 2020 Accepted: 4 June 2021

Published online: 30 June 2021

\section{References}

1. Organisation WH. Definition of Palliative Care World Health Organisation2008 [Available from: http://www.who.int/cancer/palliative/ definition/en/.

2. Connor S, M. SB. Global atlas of palliative care at the end of life Worldwide Palliative Care Alliance and World Health Organization2014 [Available from: https://www.who.int/nmh/Global_Atlas_of_Palliative_Care.pdf.

3. Ahmed N, Bestall JC, Ahmedzai SH, Payne SA, Clark D, Noble B. Systematic review of the problems and issues of accessing specialist palliative care by patients, carers and health and social care professionals. Palliat Med. 2004; 18(6):525-42.

4. Firn J, Preston N, Walshe C. What are the views of hospital-based generalist palliative care professionals on what facilitates or hinders collaboration with in-patient specialist palliative care teams? A systematically constructed narrative synthesis. Palliat Med. 2016;30(3):240-56.

5. Foundation L. Survey on death attitudes in Singapore 2014 [Available from: http://lienfoundation.org/sites/default/files/Lien\%20Fdn\%20Survey\%20of\%2 0Death\%20Attitudes\%20-\%20Doctors\%20n\%20Nurses\%20Final\%2018\%2 OJune_0.pdf

6. Skilbeck J, Mott L, Page H, Smith D, Hjelmeland-Ahmedzai S, Clark D. Palliative care in chronic obstructive airways disease: a needs assessment. Palliat Med. 1998;12(4):245-54.

7. D F, J. A-H. Extending specialist palliative care to all? Soc Sci Med 1999;48(9): 1271-1280.

8. Brickner L, Scannell K, Marquet S, Ackerson L. Barriers to hospice care and referrals: survey of physicians' knowledge, attitudes, and perceptions in a health maintenance organization. J Palliat Med. 2004;7(3):411-8.

9. Georges JJ, Grypdonck M, Dierckx de Casterle B. Being a palliative care nurse in an academic hospital: a qualitative study about nurses' perceptions of palliative care nursing. J Clin Nurs. 2002;11(6):785-93.

10. Wallerstedt B, Benzein E, Schildmeijer K, Sandgren A. What is palliative care? Perceptions of healthcare professionals. Scand J Caring Sci. 2019;33(1):77-84.

11. Alaeddini J, Julliard K, Shah A, Islam J, M. M. Physician attitudes toward palliative care at a community teaching hospital. Hosp J 2000;15(2):67-86.

12. Ansari M, Rassouli M, Akbari ME, Abbaszadeh A, AA. S. Educational needs on palliative Care for Cancer Patients in Iran: a SWOT analysis. Int I Community Based Nurs Midwifery 2018;6(2):111-124.

13. Fox J, Windsor $C$, Connell S, P. Y. The positioning of palliative care in acute care: a multiperspective qualitative study in the context of metastatic melanoma. Palliat Support Care 2016;14(3):259-268.

14. Beernaert K, Deliens L, De Vleminck A, Devroey D, Pardon K, Van den Block $L$, et al. Early identification of palliative care needs by family physicians: a qualitative study of barriers and facilitators from the perspective of family physicians, community nurses, and patients. Palliat Med. 2014;28(6):480-90. 
15. Broom A, Kirby E, Good P, Wootton J, J. A. Specialists' experiences and perspectives on the timing of referral to palliative care: a qualitative study. . J Palliat Med 2012;15(11):1248-1253.

16. Cherny NI, R. C. Attitudes of medical oncologists toward palliative care for patients with advanced and incurable cancer: report on a survery by the European Society of Medical Oncology Taskforce on palliative and supportive care. Cancer. 2003;98(11):2502-10.

17. Hui D, Bansal S, Park M, Reddy A, Cortes J, Fossella F, et al. Differences in attitudes and beliefs toward end-of-life care between hematologic and solid tumor oncology specialists. Ann Oncol. 2015;26(7):1440-6.

18. Keim-Malpass J, Mitchell EM, Blackhall L, PB. D. Evaluating stakeholderidentified barriers in accessing palliative care at an $\mathrm{NCl}$ designated cancer center with a rural catchment area. . J Palliat Med 2015;18(7):634-637.

19. Llamas KJ, Llamas M, Pickhaver AM, NB. P. Provider perspectives on palliative care needs at a major teaching hospital. Palliat Med 2001; 15(6):461-470

20. Patel MI, Periyakoil VS, Moore D, Nevedal A, TR. C. Delivering end-of-life Cancer care: perspectives of providers. Am J Hosp Palliat Care 2018;35(3): 497-504.

21. Schenker Y, Crowley-Matoka M, Dohan D, Rabow MW, Smith CB, White DB, et al. Oncologist factors that influence referrals to subspecialty palliative care clinics. J Oncol Pract. 2014;10(2):e37-44.

22. Hui D, Cerana MA, Minjeong P, Hess K, E. B. Impact of Oncologists' attitudes toward end-of-life care on Patients' access to palliative care. Oncologist. 2016;21(9):1149-1155.

23. McDarby M, BD. C. Barriers and facilitators to effective inpatient palliative care consultations: a qualitative analysis of interviews with palliative care and nonpalliative care providers. . Am J Hosp Palliat Med 2019;36(3):191-199.

24. Kafadar D, Ince N AA, M. G. Evaluation of managerial needs for palliative care centers: perspectives of medical directors. . Asian Pac J Cancer Prev 2015;16(11):4653-4658

25. Kawaguchi S, Mirza R, Nissim R, J. R. Internal medicine residents' beliefs, attitudes, and experiences relating to palliative care: a qualitative study. Am J Hosp Palliat Med 2017;34(4):366-372.

26. Mahon MM. WJ. M. Oncology nurses' personal understandings about palliative care. Oncol Nurs Forum. 2010;37(3):E141-50.

27. Rajnoveanu RM, Rajnoveanu AG, Fildan AP, Todea DA, Man MA, Motoc NS, et al. Palliative care initiation in chronic obstructive pulmonary disease: prognosis-based, symptoms-based or needs-based? Int J Chron Obstruct Pulmon Dis. 2020;15:1591-600.

28. Ho MZJ, Krishna L, ACP. Y. Chinese familial tradition and Western influences: a case study in Singapore on decision making at the end of life. . J Pain Symptom Manag 2010;40(6):932-936.

29. Krishna L. Decision making at the end of life: a Singaporean perspective. Asian Bioethics Review. 2011;3(2):118-26.

30. Yang G, Kwee A, Krishna L. Should patients and family be involved in "do not resuscitate" decisions? Views of oncology and palliative care doctors and nurses. Indian J Palliat Care. 2012;18:52-8.

31. Foo W, Zheng Y, Yang G, Kwee A, Krishna L. Factors considered in end of life decision making of health care professional. Am J Hos Pall Med. 2013;30:354-8.

32. Chai $H$, Krishna $L$, Wong V. Feeding: what it means to patients and caregivers and how these views influence Singaporean Chinese caregivers' decisions to continue feeding at the end of life. Am J Hos Pall Med. 2014; 31(2):166-71.

33. Ching J, Quah Y, Yang G, Menon S, Krishna L. Patient and family involvement in decision making for management of cancer patients at a Centre in Singapore. BMJ Support Palliat Care. 2015;5(4):420-6.

34. Qiang L. Core Culture Values and Beliefs of Singapore. Am J Culture Philosophy 2007;2(2).

35. Tan T, Teo F, Wong K. Cancer: to tell or not to tell? Singap Med J. 1993;34: 202-3.

36. Tarmugi A. Preserving family ties and family values. Luncheon talk on 'family values' at the United Nations Association of Singapore (UNAS) 1994.

37. Low J, Kiow S, Main N. Reducing collusion between family members and clinicians of patients refereed to palliative care team. Perm J. 2009;13(4):11-5.

38. Lee $\mathrm{A}, \mathrm{Wu} \mathrm{H}$. Diagnosis disclosure in cancer patients - when family says 'no!'. Singap Med J. 2002;43(10):533-8.

39. Tsai D. How should doctors approach patients? A confucian reflection on personhood. J Med Ethics. 2001;27(1):44-50
40. Ho A. Relational autonomy or undue pressure? Family's role in medical decision-making. Scand J Caring Sci. 2008:22:128-35.

41. Back M, Huak C. Family centred decision making and non-disclosure of diagnosis in a south east Asian oncology practice. Psychooncology. 2005; 14(12):1052-9.

42. Krishna L. Nasogastric feeding at the end of life: a virtue ethics approach. Nurs Ethics Nurs Ethics. 2011;18:485-94.

43. Krishna $L$. The position of the family of palliative care patients within the decision making process at the end of life in Singapore. Ethics Med. 2011; 27(3):183-90.

44. Krishna LK. Palliative care imperative: a framework for holistic and inclusive palliative care. Ethics Med. 2013;29(1):41-61.

45. Krishna LK, Watkinson DS, Beng NL. Limits to relational autonomy--the Singaporean experience. Nurs Ethics. 2015;22(3):331-40.

46. JA L, Ng WC, KB Y. End-of-life issues - preferences and choices of a group of elderly Chinese subjects attending a day care Centre in Singapore. Ann Acad Med Singap. 2000;29(1):50-6.

47. Chan D, Goh L. The doctor-patient relationship: a survey of attitudes and practices in Singapore. Bioethics. 2000;14(1):58-76.

48. Mehta K. Stress among family caregivers of older persons in Singapore. J Cross Cult Gerontol. 2006;20(4):319-34.

49. Low $\mathrm{S}$. 'Who is responsible for this patient?' A case study analysis of conflicting interests between family, patient and doctor in a Singaporean context. Asian Bioeth Rev. 2011:3(3):261-71.

50. Cong Y. Doctor-family-patient relationship: the Chinese paradigm of informed consent. J Med Philos. 2004:29(2):148-78.

51. Pang M. Protective truthfulness: the Chinese way of safeguarding patients in informed treatment decisions. J Med Ethics. 1999;25(3):247-53.

52. Toh $\mathrm{H}$. Providing hope in terminal cancer: when is it appropriate and when is not? Ann Acad Med Singap. 2011;40:50-5.

53. LK. K. Dispelling myths, new and old, surrounding the practice of continuous sedation until death. . Asian Bioethics Review. 2014;6(3):259-288.

54. Wentlandt K, Krzyzanowska MK, Swami N, Rodin GM, Le LW, Zimmermann C. Referral practices of oncologists to specialized palliative care. J Clin Oncol. 2012:30(35):4380-6.

55. Rodriguez R, Marr L, Rajput A, Fahy BN. Utilization of palliative care consultation service by surgical services. Annals of Palliative Medicine. 2015; 4(4):194-9.

56. Cancer pain relief and palliative care. Report of a WHO Expert Committee. World Health Organization - Technical Report Series: World Health Organization; 1990 [Available from: https://apps.who.int/iris/bitstream/ha ndle/10665/39524/WHO_TRS_804.pdf?sequence=1\&isAllowed=y.

57. Council SH. National Guidelines for Palliative Care and Interpretation Guide 2015 [Available from: https://singaporehospice.org.sg/site2019/wp-content/ uploads/National-Guidelines-for-Palliative-Care-Revised-Ed.-Jan-2015.pdf.

58. Josephine M. Clayton, Karen M Hancock, Phyllis N Butow, Tattersall MHN, Currow DC. Clinical practice guidelines for communicating prognosis and end of life issues with adults in the advanced stages of a life-limiting illness, and their caregivers. Med J Aust. 2007;186(12):S77-S105.

59. Physicians. RCo. Talking about dying: How to begin honest conversations about what lies ahead. Our future health 2018 [Available from: https://www. rcplondon.ac.uk/projects/outputs/talking-about-dying-how-begin-honestconversations-about-what-lies-ahead.

60. Murtagh FE, Ramsenthaler C, Firth A, Groeneveld El, Lovell N, Simon ST, et al. A brief, patient- and proxy-reported outcome measure in advanced illness: validity, reliability and responsiveness of the integrated palliative care outcome scale (IPOS). Palliat Med. 2019;33(8):1045-57.

61. Waller A, Girgis A, Davidson PM, Newton PJ, Lecathelinais C, Macdonald PS, et al. Facilitating needs-based support and palliative care for people with chronic heart failure: preliminary evidence for the acceptability, inter-rater reliability, and validity of a needs assessment tool. J Pain Symptom Manag. 2013:45(5):912-25

\section{Publisher's Note}

Springer Nature remains neutral with regard to jurisdictional claims in published maps and institutional affiliations. 